\title{
A Computational Study on Mixed Convection Heat Transfer in an Inclined Rectangular Channel under Imposed Local Flow Modulation
}

\author{
Mohammad Nasim Hasan ${ }^{\star}$, Clinton Chowdhury, Kawser Ahmed Jewel, Sumon Saha \\ Department of Mechanical Engineering, Bangladesh University of Engineering and Technology, BUET, \\ Dhaka, 1000, Bangladesh, *Email: nasim@me.buet.ac.bd
}

\begin{abstract}
Numerical investigation of mixed convection heat transfer in an inclined 2D rectangular channel provided with partially heated bottom wall and a constant low temperature upper wall has been performed. The heated section of the bottom wall i.e. the heaters are maintained with constant heat flux and separated from each other by adiabatic segments. A fully developed parabolic velocity profile at constant low temperature is induced at the inlet. To enhance the heat transfer from the heaters, local flow field in the channel is modulated by placing circular cylinders rotating in counterclockwise direction (aiding flow) above each heater along the channel centerline. The fluid and the thermal fields within the rectangular channel are governed by the two-dimensional Navier-Stokes and Energy equations that have been solved by adapting Galerkin finite element method. The governing parameters of the present problem such as Reynolds number $(R e)$ and Grashof number $(G r)$ are varied in the range of $1 \leq R e \leq 100$ and $10^{3} \leq \mathrm{Gr} \leq 10^{5}$. Air has been considered as working fluid having a Prandtl number, $\operatorname{Pr}=0.71$. In addition to these governing parameters, the inclination angle of the channel $(\alpha)$ and the speed ratio $(\xi)$ that is the ratio of peripheral speed of the rotating cylinder and the maximum inlet flow velocity is also varied in the range of $0^{\circ} \leq \alpha \leq 90^{\circ}$ and $0.5 \leq \xi \leq 2.0$ respectively. The thermal and the fluid fields are visualized via the isotherm and the streamline plots. The efficacy of local flow modulation with rotating cylinder for heat transfer enhancement has been estimated in terms of normalized average Nusselt number over the heaters as $\mathrm{Nu} / \mathrm{Nu} u_{n c}$, where $\mathrm{Nu}$ and $N u_{n c}$ represents the average Nusselt number with and without flow modulation respectively. Results obtain in the present study reveals that, for very weak flow $(\operatorname{Re}=1)$, flow modulation results in lower heat transfer particularly at lower values of $\mathrm{Gr}$ on the contrary for moderate and higher values of $\operatorname{Re}(10,100)$, flow modulation has been found to result in higher heat transfer particularly at lower values of Gr. For example, at $\mathrm{Re}=100$ and $\alpha=0^{\circ}$, about $32 \%$ to $55 \%$ enhancement in heat transfer has been obtained for $10^{3} \leq \mathrm{Gr} \leq 10^{5}$. Variation in heat transfer enhancement through flow modulation has also been noticed for different channel inclination angle $(\alpha)$ for various system configurations.
\end{abstract}

Keywords: Mixed Convection, Local Flow Modulation, Rotating Cylinder, Isoflux Flat Heaters.

\section{Introduction}

Mixed convection being one of the most widely encountered phenomena in industrial and engineering studies, it has numerous enormous applications in industrial sectors such as heat exchangers, nuclear power plants, chemical vapor deposition and cooling of electronic equipment etc. Many researchers have focused on combined heat transfer of natural and forced convection in different types of geometry with or without the presence of an active body. Such as, Guimaraes and Menon [1] studied the effect of inclination angle, $R e$ and $G r$ on mixed convection in a rectangular channel. Use of discrete heater is also seemed to be of great interest to researchers now-a-days. Dogan et al. [2] and Muftuoglu and Bilgen [3] used discrete heaters in their studies. However, Dogan et al. [2] experimentally investigated mixed convection in a horizontal channel having arrays of discrete heater and also studied the effect of aspect ratio (AR=2, 4 and 10) at various $R e$ and Gr. Muftuoglu and Bilgen
[3] investigated the positions of discrete heaters where optimum heat transfer occurs and found that when the discrete heaters are placed closer to the bottom the best thermal performance is obtained. Obstacles inside a channel are also of interest to many researchers. Silva et al. [4] also studied heat transfer through a vertical open channel having distributed heaters. However, use of active body inside an enclosure also attracted interest of many researchers e.g. Costa and Raimundo [5] observed the effect of inserting an active cylinder insider a differentially heated square enclosure on mixed convection. Salam et al. [6] also focused mixed convection in a square enclosure with an active rotating cylinder. Bae et al. [7] investigated mixed convection in a channel having porous multi-blocks under imposed thermal flow modulation and found that heat transfer rate at the most upstream heater is enhanced by the presence of porous block. Premachandran and Balaji [8] investigated mixed convection from horizontal channel with protruding heat sources. Their study indicated that the

\footnotetext{
Corresponding Author: Mohammad Nasim Hasan

Email: nasim@me.buet.ac.bd
} 
temperature was a nonlinear decreasing function of increasing $R e$ and a linear decreasing function of increasing Gr. Furthermore, Sharma et al.[9]investigated flow structure and heat transfer characteristics in a baffled grooved channel, differentially heated from the sides and showed that for maximum heat transfer enhancement the optimum height of the baffle should be above 0.50 at any location. Rahman et al. [10] studied mixed convection in an open channel with a square cavity which has partially or fully heated on left side. Active modulation of flow inside a channel is recently given much more importance. Recently, Takahashi et al. [11] studied the effect of inserting a rotating cylinder in a channel and found an effective way to achieve heat transfer enhancement by dynamic flow control method. Further, Billah et al. [12] also studied mixed convection in a channel through active flow modulation using a circular cylinder which was rotating in either clockwise or counter-clockwise direction and found strongly dependency on type of configuration and rotation of cylinder of heat transfer.

From the above literature review, it is evident that mixed convection heat transfer inside an inclined rectangular channel having partially heated bottom wall i.e. multiple discrete heaters with local flow modulation through rotating cylinders has not been studied yet. Therefore, this work emphasized on the effect of rotating circular cylinders in aiding flow configuration of an inclined rectangular channel having multiple discrete heaters in its bottom wall. Further, the effect of various governing parameters such as Reynolds number (Re), Grashof number $(G r)$, cylinder speed ratio $(\xi)$ and channel inclination angle $(\alpha)$ has been studied extensively.

\section{Mathematical Model}

A two-dimensional rectangular channel of length $L$, height $H$, being at inclination angle $\alpha$ with the horizontal and having three rotating circular cylinders (diameter $0.5 \mathrm{H}$ ) is chosen for the present study as illustrated in Fig. 1. The length of the channel is considered to be $\mathrm{L}=9 \mathrm{H}$ and three discrete isoflux $\left(q^{\prime}\right)$ flat heaters of finite length $(B=$ $H)$ are placed along the bottom wall at $x_{1}=2 H, x_{2}=$ $4 \mathrm{H}$ and $x_{3}=6 \mathrm{H}$ while the rest of the lower wall is kept adiabatic. The upper wall of the channel is maintained at constant low temperature, $\mathrm{T}_{\mathrm{c}}$. To induce local flow modulation, three adiabatic rotating cylinders are centrally placed over each of the isoflux heaters along the channel centerline $\left(y_{c}=0.5 \mathrm{H}\right)$. Air is entering the channel through the inlet with constant low temperature $\left(T=T_{c}\right)$ with a fully developed parabolic profile having maximum velocity, $U_{\max }$ at the channel centerline as shown in Fig. 1.

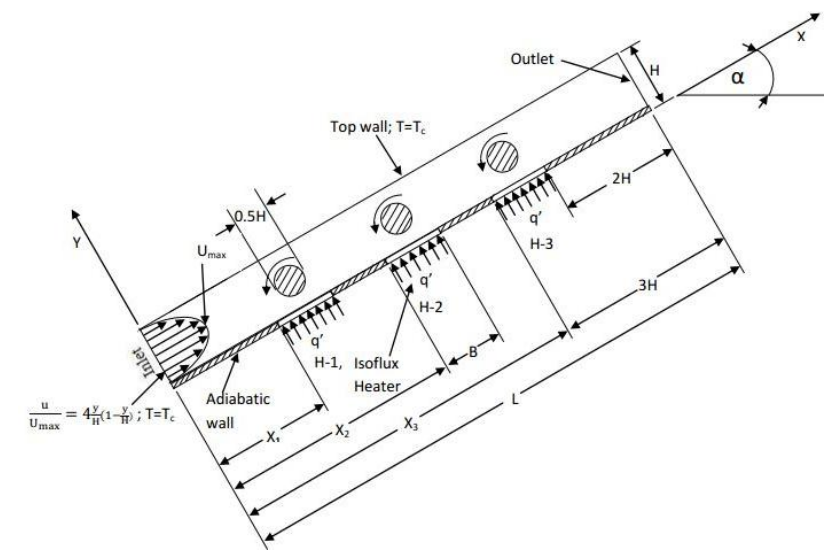

Fig.1.Schematic view of the considered mathematical model

The present study was conducted by considering the system to be laminar, incompressible and steady-state. The flow is assumed to be twodimensional inside the cavity. Dimensionless governing equation in pressure-velocity formulation can be obtained by using the following dimensionless variables

$$
X=\frac{x}{H}, Y=\frac{y}{H}, U=\frac{u}{U_{\max }}, P=\frac{p}{\rho_{0} U_{\max }{ }^{2}}, \xi=\frac{V_{p}}{U_{\max }} \theta=\frac{T-T_{0}}{\frac{q^{\prime} B}{D_{T}}},
$$

where, $\mathrm{x}, \mathrm{y}$ are the dimensional Cartesian coordinates, $X$ and $Y$ are the non-dimensional Cartesian coordinates, $\mathrm{u}, \mathrm{v}$ are the dimensional velocity components in the $x$ and $y$-directions respectively, $U$ and $V$ are the non-dimensional velocity components in the $X$ and $Y$ directions respectively, $p$ is the dimensional pressure and $P$ is the non-dimensional pressure, $D_{T}$ is thermal diffusivity of the fluid, $T$ is the dimensional temperature and $\theta$ is the non-dimensional temperature, $U_{\max }$ is the maximum velocity of the air at the inlet and $v_{p}$ is the peripheral speed of the rotating cylinders. Considering the OberbeckBoussinesq approximation for buoyancy and assuming all fluid properties are constant, the dimensionless Navier-Stokes and Energy equations in pressure-velocity formulation for a Newtonian fluid for the above dimensionless variables can be written in Eqs. (2-5).

$$
\begin{aligned}
& \frac{\partial U}{\partial X}+\frac{\partial V}{\partial Y}=0 \\
& U \frac{\partial U}{\partial X}+V \frac{\partial U}{\partial Y}=-\frac{\partial P}{\partial X}+\frac{1}{R e}\left(\frac{\partial^{2} U}{\partial X^{2}}+\frac{\partial^{2} U}{\partial Y^{2}}\right)+\frac{G r}{R e^{2}} \sin (\alpha) \theta \\
& U \frac{\partial U}{\partial X}+V \frac{\partial U}{\partial Y}=-\frac{\partial P}{\partial Y}+\frac{1}{R e}\left(\frac{\partial^{2} V}{\partial X^{2}}+\frac{\partial^{2} V}{\partial Y^{2}}\right)+\frac{G r}{R e^{2}} \operatorname{Cos}(\alpha) \theta \\
& U \frac{\partial \theta}{\partial X}+V \frac{\partial \theta}{\partial Y}=\frac{1}{\operatorname{PrRe}}\left(\frac{\partial^{2} \theta}{\partial X^{2}}+\frac{\partial^{2} \theta}{\partial Y^{2}}\right)
\end{aligned}
$$


The dimensionless governing parameters used in (3-5) are known as the Reynolds number $(R e)$, Grashof number $(\mathrm{Gr})$ and Prandtl number $(\mathrm{Pr})$ that are defined as follows:

$$
R e=\frac{U_{\max } H}{v}, G r=\frac{g \beta \Delta T H^{3}}{v^{2}}, \operatorname{Pr}=\frac{v}{D_{T}} .
$$

The relationship between the stream functions $(\Psi)$ and the velocity components $(\mathrm{U}, \mathrm{V})$ are:

$$
\begin{aligned}
& U=\frac{\partial \Psi}{\partial Y}, V=-\frac{\partial \Psi}{\partial X}, \\
& \frac{\partial^{2} \Psi}{\partial X^{2}}+\frac{\partial^{2} \Psi}{\partial Y^{2}}=\frac{\partial U}{\partial Y}-\frac{\partial V}{\partial X} .
\end{aligned}
$$

Since, the channel walls are solid and stationary; therefore, no-slip condition exists on the walls. However, the circular cylinders are rotating with constant speed and the thermal condition is kept adiabatic.

Table 1.Boundary conditions of the present problem

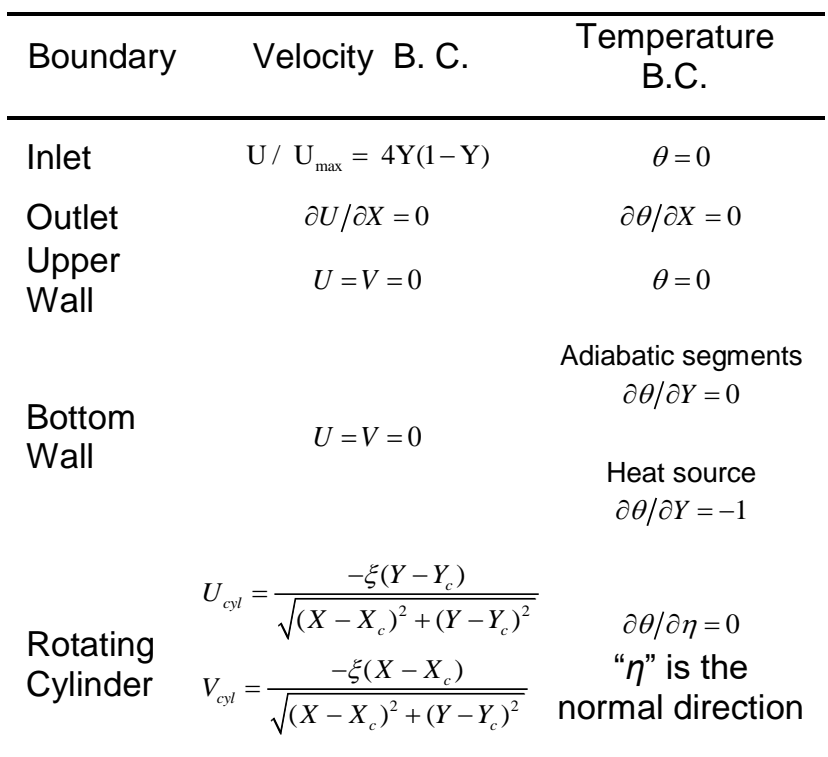

The average Nusselt number along a surface of length " $s$ " can be written as,

$N u_{\text {avg }}=\frac{1}{s} \int \frac{1}{\theta} d s$,

To estimate the effectiveness of the local flow modulation for heat transfer enhancement via rotating cylinder with respect to the base case (no cylinder condition), the normalized Nusselt number has been expressed in terms of the ratio of the average Nusselt number of the heater with rotating cylinders to that of no cylinder condition as follows:

$$
N u / N u_{n c}=\frac{N u_{\text {avg, Rotating-cylinder }}}{N u_{\text {avg }, N o-c y l i n d e r}} .
$$

\section{Numerical Methodology and Model Validation}

In order to investigate the thermal and flow behaviors in the rectangular channel, Galerkin weighted residual method of finite element formulation is used in the present work. The computational domain is discretized into nonuniform triangular elements in order to solve the non-dimensional variables. Finer mesh near the solid boundary and comparatively coarser mesh around the center region of the channel are employed for getting more accurate result due to the fact that dependent variables change rapidly near the boundary. The precision of the computation method is examined via grid validation check. Nine different non-uniform meshes are employed to check the sensitivity of the grid. The grid sensitivity check is performed at $\operatorname{Re}=100, \mathrm{Gr}=10^{4}$ and $\alpha=$ $0 \circ$, which is shown in Fig. 2. It is evident from the figure that the average Nusselt number becomes almost constant at about elements number of 13222 which is selected for further computations for this investigation.

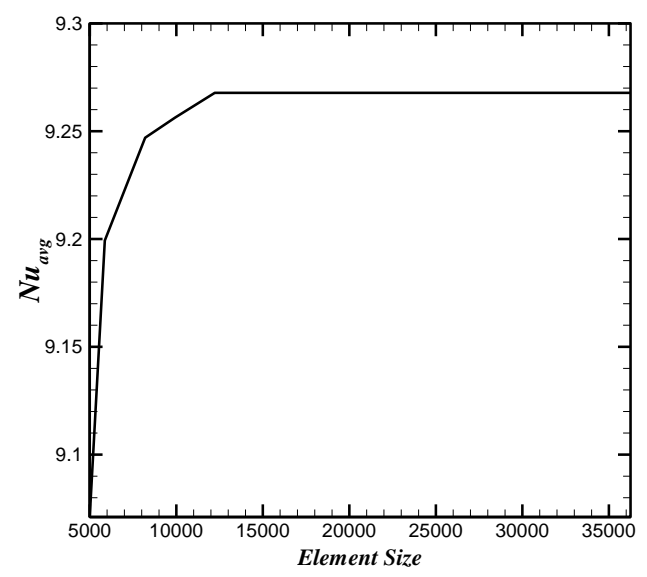

Fig.2.Variation of average Nusselt number along with different element size for $\operatorname{Re}=100, \mathrm{Gr}=10^{4}$ and $\alpha=0^{\circ}$.

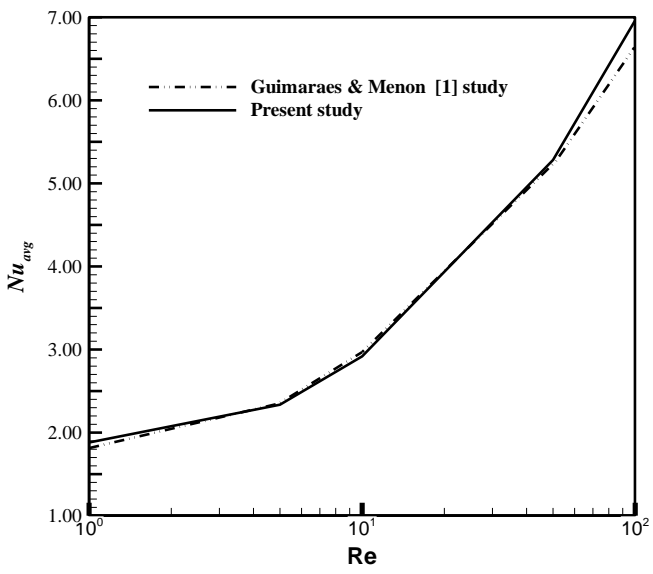

Fig.3.Comparison of average Nusselt number of Guimaraes and Menon study [1] with the present study. 
In order to check the accuracy of the present computational model a validation check of the average Nusselt number for the present numerical model is compared with Guimaraes and Menon [1] in Fig. 3. The average Nusselt number for both the model is evaluated at $\mathrm{Gr}=10^{3}$ and $\alpha=0^{\circ}$. From Fig. 2 , it can be confirmed that there is an excellent agreement between the two studies. Therefore, we can claim that the present approach is suitable for further use with satisfactory accuracy.

\section{Results and Discussion}

In the present study numerical simulations on mixed convection in an inclined rectangular channel has been performed, containing partially heated bottom wall connected by adiabatic segments, where rotating cylinders are inserted above each of the heaters. Cylinders are rotated in counterclockwise direction at different speeds which are adiabatic. Air is considered as the working fluid inside the channel with the fixed $\operatorname{Pr}=0.71$. Simulations have been performed by varying $\mathrm{Gr}$ from $10^{3} \sim 10^{5}$, inclination angle $(\alpha)$ from $0^{\circ} \sim 90^{\circ}$, speed ratios of cylinders $(\xi)$ from $0.5 \sim 2.0$ at $\operatorname{Re}$ from $1 \sim 100$ to inspect the effect of heat transfer characteristics of heaters in the channel. Temperature field and flow field are properly investigated in terms of isothermal lines and streamlines respectively. Heat transfer visualization is also performed in terms of Normalized Nusselt number $\left(\mathrm{Nu} / \mathrm{Nu}_{\mathrm{nc}}\right)$.

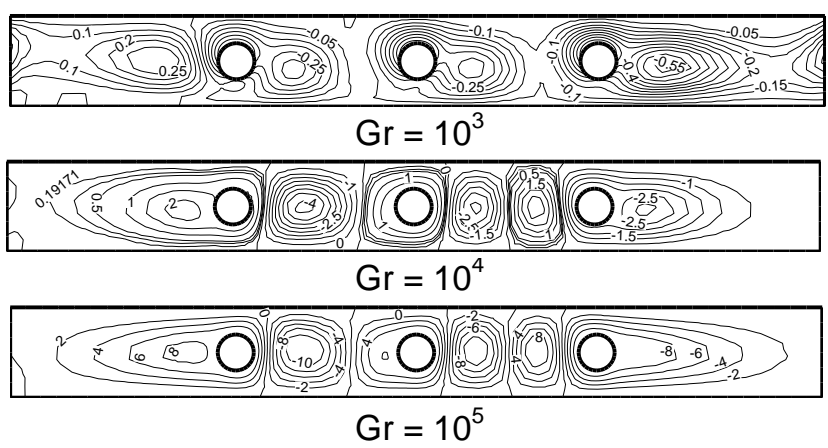

Fig.4.Variation of streamlines with $\mathrm{Gr}$ at $\operatorname{Re}=1, \alpha=$ $0^{\circ}$ and $\xi=1.0$.

In Fig.4, the effect of Gr on streamlines is depicted at $R e=1.0$. Local flow modulation generated by the rotation of cylinder creates secondary circulation which becomes stronger with increasing $\mathrm{Gr}$. At $\mathrm{Gr}=$ $10^{3}$ secondary circulation is very weak and $\mathrm{Gr}=10^{4}$ and $10^{5}$ with the increase of buoyancy force secondary circulation turn into strong to stronger. At lower Re cylinder works like an obstacle and so inertia force become weaker after passing through each of the cylinders which makes the flow discontinuous also. With the decrease of inertia force each cylinder creates its own secondary circulation adjacent to it, which can be seen between second and third cylinder at $\mathrm{Gr}=10^{4}$ and $10^{5}$.

Fig. 5 describes the effect of $\mathrm{Gr}$ on streamlines at $\operatorname{Re}=10$. At lower $\mathrm{Gr}$, flow is continuous due to comparatively higher inertia force. At $\mathrm{Gr}=10^{4}$, flow start to become discontinuous along with the creation of secondary circulation due to higher buoyancy force. At $\mathrm{Gr}=10^{5}$, secondary circulation is completely created and flow becomes discontinuous.

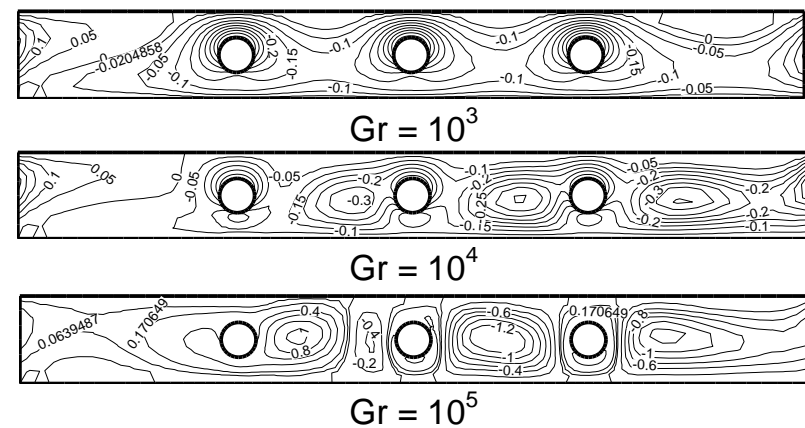

Fig.5.Variation of streamlines with $\mathrm{Gr}$ at $\mathrm{Re}=10$, $\alpha=0^{\circ}$ and $\xi=1.0$.

Fig. 6 demonstrates the pattern of streamlines at $R e$ $=100$ where flow is very strong and secondary circulation is completely eliminated due to high inertia force. With the increasing of $G r$, flow pattern is hardly changed and remains continuous throughout the channel.

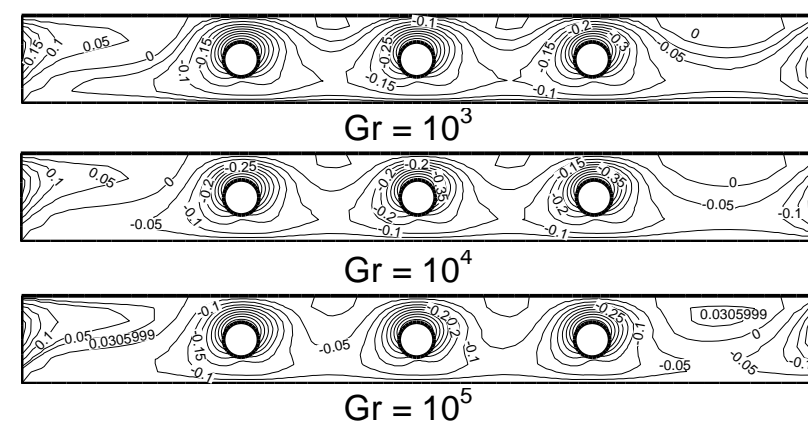

Fig.6.Variation of streamlines with $\mathrm{Gr}$ at $\mathrm{Re}=100$, $\alpha=0^{\circ}$ and $\xi=1.0$.

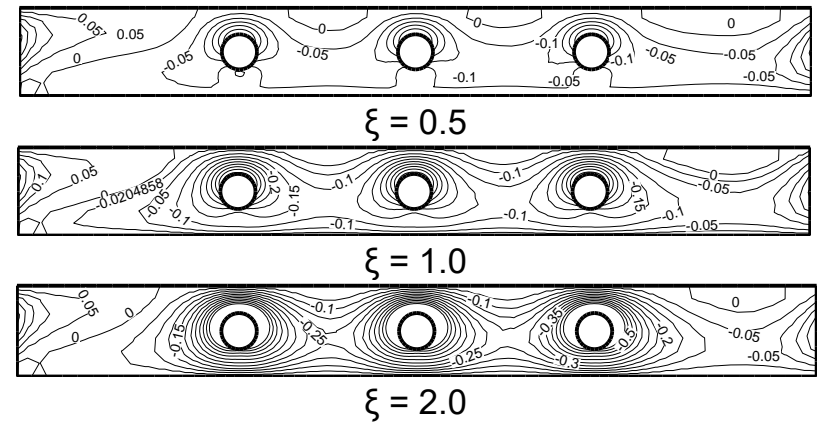

Fig.7.Variation of Streamlines with $\xi$ at $\operatorname{Re}=10$ and $\mathrm{Gr}=10^{3}$ and $\alpha=0^{\circ}$. 
Fig. 7 illustrates the effect of speed ratios on streamlines at $\mathrm{Re}=10$ and $\mathrm{Gr}=10^{3}$. At low speed ratio, $\xi=0.5$ circulation is weak and attached with cylinders. At $\xi=1.0$, circulation becomes stronger than before but still remains attached with the cylinder walls. At $\xi=2.0$, due to higher rotation of cylinder, more strong circulation of flow is created which is separated from cylinder wall and fully spread out along height of the channel.

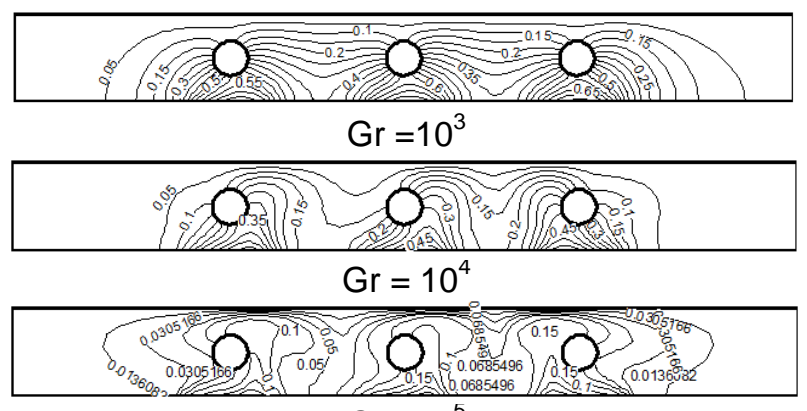

$\mathrm{Gr}=10^{\mathrm{b}}$

Fig.8. Variation of Isotherm lines with $\mathrm{Gr}$ at $R e=1$ and $\alpha=0^{\circ}$ and $\xi=1.0$.

Fig. 8 narrates effect of $\mathrm{Gr}$ on isotherm lines at $R e$ $=1$. At $\mathrm{Gr}=10^{3}$, due to lower buoyancy force, isotherm lines are approximately dome shaped and parallel to each other which indicates conduction dominated mixed convection.

At higher Gr, dome shaped is distorted by the rotation of cylinders and due to more buoyancy force which means that heat transfer is convection dominated and this phenomenon becomes prominent at $\mathrm{Gr}=10^{5}$.

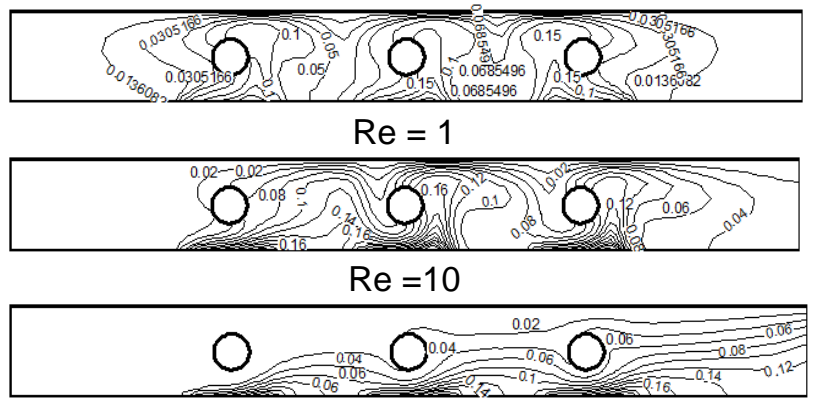

$\mathrm{Re}=100$

Fig.9.Variation of Isotherm lines with $\mathrm{Re}$ at $\mathrm{Gr}=10^{5}$ at $\alpha=0 \circ$ and $\xi=1.0$.

Fig. 9 depicts the effect of $\mathrm{Re}$ on isotherm lines at $\mathrm{Gr}=10^{5}$. At lower $\mathrm{Re}=1$, shape of isotherm lines depend mainly on buoyancy force and distortion of isotherm lines are noticeable due to rotation of cylinders. At higher $\mathrm{Re}$, dome shaped goes rightward due to high inertia force and effect is more significant at $\mathrm{Re}=100$ where isotherm lines are approximately straight through the channel and effect of rotation of cylinder is less dominant.

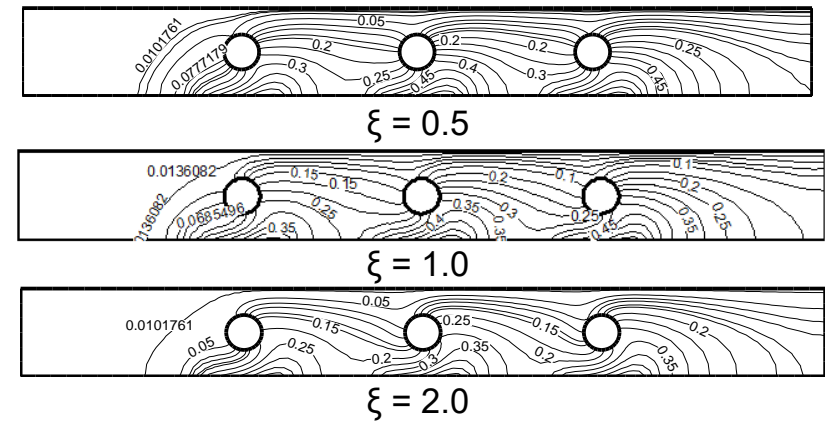

Fig. 10. Variation of Isotherm lines with $\xi$ at $\mathrm{Re}=10$ and $\mathrm{Gr}=10^{3}$ and $\alpha=0^{\circ}$.

Fig.10 depicts the effect of speed ratios on isotherm lines at $\mathrm{Re}=10$ and $\mathrm{Gr}=10^{3}$. At speed ratio, $\xi=$ 0.5 isotherm lines are hardly distorted due to lower rotational speed of cylinders. At higher speed ratio isotherm lines are highly distorted at counterclockwise direction by the rotation of cylinders and tried to become straight at downstream of channel.

Fig.11 shows the effect of $\mathrm{Gr}$ on Normalized Nusselt number $\left(\mathrm{Nu} / \mathrm{Nu}_{\mathrm{nc}}\right)$ of three heaters for different speed ratios $(\xi)$ at $\operatorname{Re}=1,10$ and 100 at horizontal channel $\left(\alpha=0^{\circ}\right)$. Normalized Nusselt number is used to compare the heat transfer characteristics when cylinders are added above the heaters with no cylinder condition. At $\mathrm{Re}=1.0$, lower $\mathrm{Gr}=10^{3}$ and $\mathrm{Gr}=10^{4}, \mathrm{Nu} / \mathrm{Nu}_{\mathrm{nc}}$ is less than 1.0 which indicates that heat transfer is decreasing and addition of cylinders across the heaters acts like an obstacle. But at $\mathrm{Gr}=10^{5}$,addition of cylinders enhances heat transfer around $5 \%$ at Heater $-1,10 \%$ at Heater-2 and $15 \%$ at Heater-3. Here heat transfer is not increased considerably due to very weak flow $(\mathrm{Re}=$ 1.0) and addition of cylinders are less effective for this condition .At higher speed ratio, $\xi=2.0$ heat transfer is more than other two speed ratios. At moderate flow $(\operatorname{Re}=10)$ and $\xi=0.5$ heat transfer increases $6 \%$ for Heater-1, $9 \%$ for Heater-2, where heat transfer is almost constant with increasing $\mathrm{Gr}$. But at Heater-3 heat transfer increases 35\% at lower to moderate $\mathrm{Gr}$ and around $20 \%$ for higher $\mathrm{Gr}$. In this condition at $\xi=1.0$ heat transfer increases around $10 \% \sim 20 \%$ for all heaters due to flow modulation. At $\xi=2.0$, heat transfer is most for Heater-1 \& Heater-2 than other two lower speed ratios around 15\% 35\% and decreases at higher Gr. But in this condition at Heater-3 heat transfer increases around $15 \%$ due to addition of cylinders.

In Fig 11 at $\operatorname{Re}=100$ and $\xi=0.5$, heat transfer increases $32 \%$ for Heater-1, 22\% for Heater-2 and $18 \%$ for Heater-3.At $\xi=1.0$, increase of heat transfer is $40 \%$ for Heater-1, $28 \%$ for Heater-2 and $21 \%$ for Heater-3. Results demonstrate that increase of speed ratio enhance the heat transfer which is also true for $\xi=2.0$. Here, heat transfer increases $55 \%$ for Heater-1, $42 \%$ for Heater-2 and 

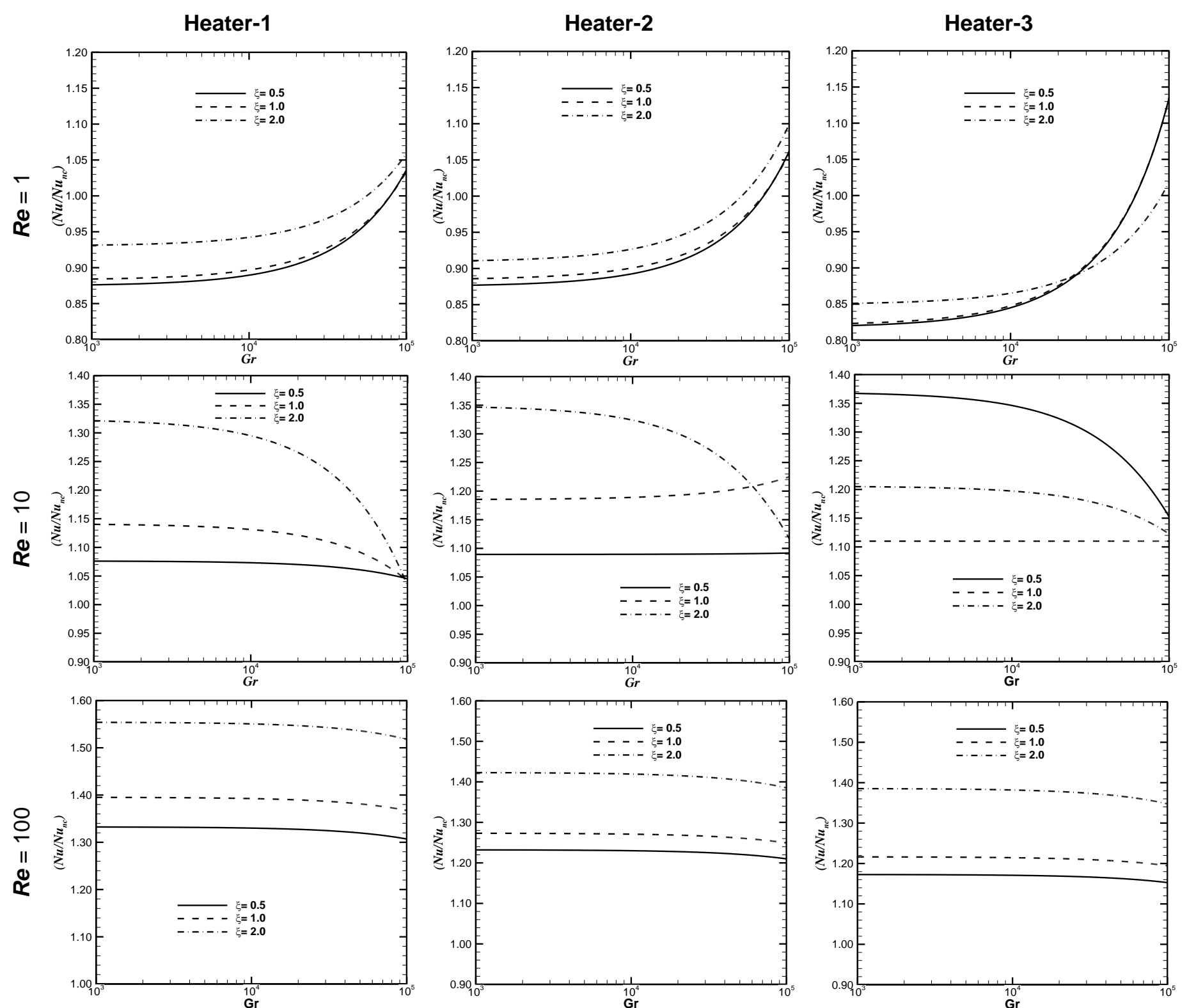

Fig.11. Effect of $\mathrm{Gr}$ on Normalized Nusselt number for different heaters at different speed ratios at $\mathrm{Re}=1$, 10 and 100 and at $\alpha=0^{\circ}$.

$38 \%$ for Heater-3.This study depicts that addition of cylinder at higher $\operatorname{Re}(=100)$ enhances heat transfer considerably than no cylinder condition. At Heater-1, heat transfer is more than other two heaters, as more hot fluid is passed through Heater-2 and Heater-3. For all cases, $\mathrm{Nu} / \mathrm{Nu}_{\mathrm{nc}}$ remains almost constant with the increase of $\mathrm{Gr}$.

Fig. 12, depicts the effect of inclination angle of channel $(\alpha)$ on $\mathrm{Nu} / \mathrm{Nu}_{\mathrm{nc}}$ at $\mathrm{Re}=1,10$ and 100 at $\mathrm{Gr}$ $=10^{5}$ for three heaters at different speed ratios. For Heater-1, $\mathrm{Nu} / \mathrm{Nu}_{\mathrm{nc}}$ is always greater than 1.0 for all inclination angles, because Heater- 1 is situated at close to entrance of flow. For Heater-2 and Heater3 , addition of cylinders is only effective for approximately horizontal channel $\left(\alpha=0^{\circ} \sim 10^{\circ}\right)$. At higher inclination angle, addition of cylinder has negative effect on heat transfer due to gravitational and rotational effect. At $\mathrm{Re}=100$, Heater -1 is almost 30\% 50\% efficient at all inclination angles. For all heaters heat transfer decreases with increasing a due to more gravitational force acting at opposite direction of the flow. At Heater-3 performance is very low at higher inclination angle.

\section{Conclusion}

The effect of local flow modulation using circular rotating cylinders on heat transfer during mixed convection in a 2-D inclined channel with partially heated bottom wall was the main focus of the present study. The study has been performed for a wide range of various system parameters such as, Reynolds Number $(1 \leq R e \leq 100)$, Grashof number $\left(10^{3} \leq G r \leq 10^{5}\right)$, Cylinder peripheral 

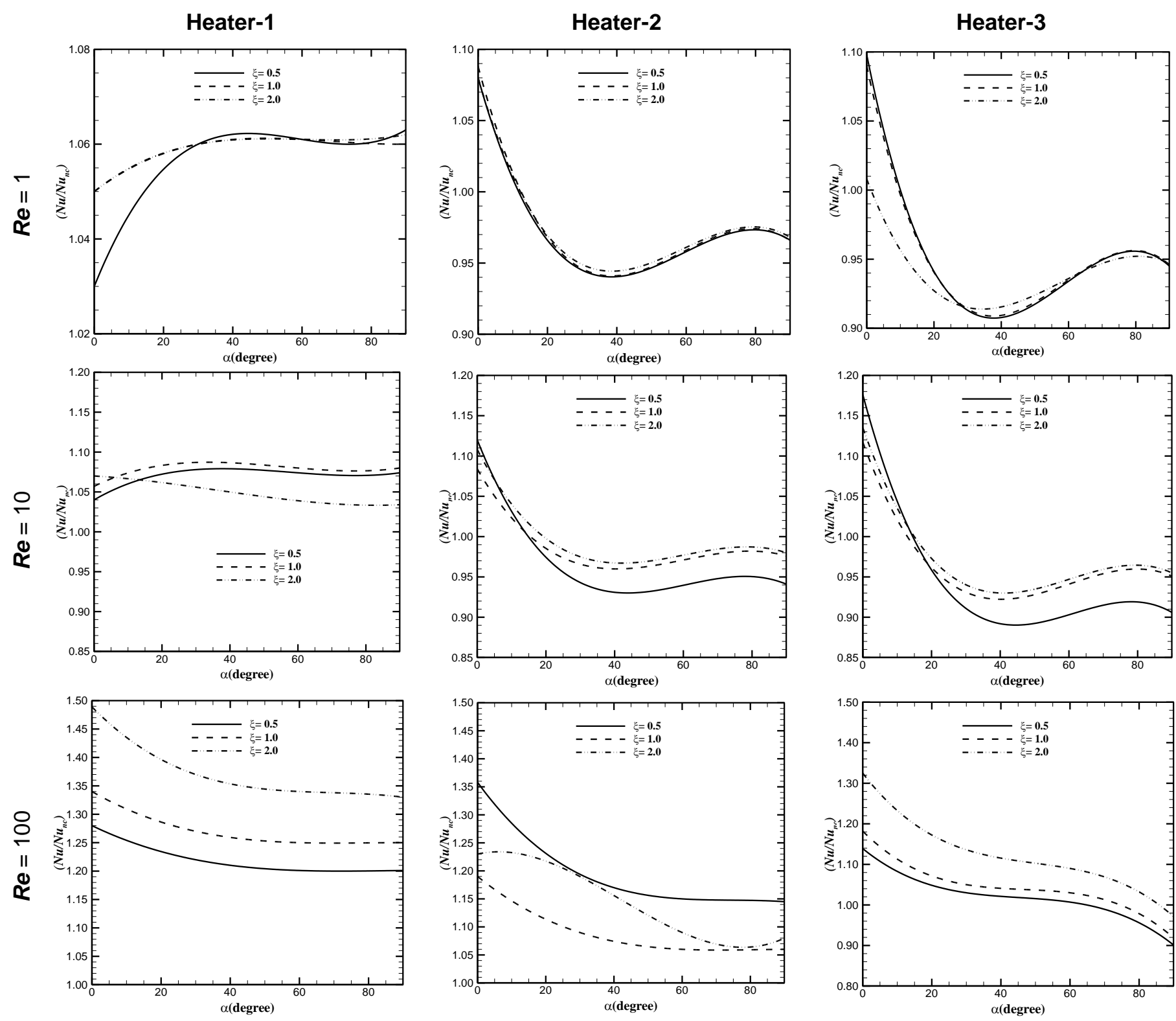

Fig.12. Variation of Normalized Nusselt Number with Inclination angle at different speed ratio at $\operatorname{Re}=1,10$ and 100 at $\mathrm{Gr}=10^{5}$.

speed to maximum inflow velocity ratio $(0.5 \leq \xi \leq$ 2.0) and channel inclination angle $\left(0^{\circ} \leq \alpha \leq 90^{\circ}\right)$. From this study, following results have been obtained-

- Inertia force favors the flow field to be continuous across the channel while buoyancy force is liable for local secondary circulation. For very weak flow $(R e=1.0)$, secondary circulation is created and gradually becomes stronger with increasing Gr. On the contrary at moderate to higher values of $\mathrm{Re},(10 / 100)$ secondary circulation diminishes gradually and flow becomes continuous therefore heat transfer enhancement occurs.
- Local flow modulation may even decrease heat transfer when the modulators act as flow obstacles at lower values of $R e$ and Gr.

- Heat transfer enhancement due to local flow modulation has been found to depend on the location of the heater itself.

- With increasing speed ratio of the rotating cylinder, influence of local flow modulation on channel main flow in increased. Distortion of isotherm lines is more at higher speed ratio compared to lower speed ratio.

- At lower values of Re, flow modulation is only effective for higher values of $\mathrm{Gr}$. For moderate to higher values of $R e$, heat transfer enhances around $25 \%$ to $55 \%$ for different cases by flow modulation with rotating cylinder. 
- Flow modulation is always effective for approximately horizontal channel $\left(\alpha=10^{\circ}\right)$ at weak to moderate flow condition but for higher Re such as $R e=100$, effectiveness prevailed up to much higher inclination angle $\left(\alpha=80^{\circ}\right)$.

\section{Nomenclature}

$\begin{array}{ll}\mathrm{g} & \text { Gravitational acceleration } \\ \mathrm{D}_{T} & \text { Fluid thermal diffusivity } \\ \mathrm{H} & \text { Channel height } \\ \mathrm{L} & \text { Channel length } \\ \mathrm{Re} & \text { Reynolds number } \\ \mathrm{Gr} & \text { Grashof number } \\ \mathrm{q}^{\prime} & \text { Constant heat flux } \\ \mathrm{Pr} & \text { Prandtl number } \\ \mathrm{Nu} / \mathrm{Nu} \mathrm{n}_{\mathrm{n}} & \text { Normalized Nusselt number } \\ \mathrm{p} & \text { Dimensional pressure } \\ \mathrm{P} & \text { Non dimensional pressure } \\ \mathrm{T} & \text { Temperature } \\ \mathrm{T}_{\mathrm{c}} & \text { Inlet and upper wall temperature } \\ \mathrm{u}, \mathrm{v} & \text { Velocity component along } \mathrm{x} \text { and } \mathrm{y} \\ \mathrm{U}, \mathrm{V} & \text { Non-dimensional velocity } \\ & \text { component along } \mathrm{x} \text { and } \mathrm{y} \\ \mathrm{V}_{\mathrm{p}} & \text { Peripheral speed of the rotating } \\ & \text { cylinder } \\ \mathrm{x}, \mathrm{y} & \text { Dimensional co-ordinate } \\ \mathrm{X}_{\mathrm{c}}, \mathrm{y}_{\mathrm{c}} & \text { Centre of rotating cylinder } \\ \mathrm{X}, \mathrm{Y} & \text { Non-dimensional co-ordinate }\end{array}$

Greek Symbol

$\begin{array}{ll}\ominus & \text { Non dimensional temperature } \\ \xi & \text { Speed ratio }\left(V_{p} / U_{\max }\right) \\ v & \text { Kinematic viscosity } \\ \alpha & \text { Inclination angle } \\ \eta & \text { Normal direction }\end{array}$

\section{References}

1. P. M. Guimarães and G. J. Menon. Mixed convection in an inclined rectangular channel with a discrete heat source, Int. Communications in Heat and Mass Transfer 1667-1680 (2003).

2. A. Dogan, M. Sivrioglu, and S. Baskaya. Investigation of mixed convection heat transfer in a horizontal channel with discrete heat sources at the top and at the bottom, Int.
J. Heat and Mass Transfer.49, 2652-2662 (2006).

3. E. Bilgen and A. Müftüoğlu. Natural convection in an open square cavity with discrete heaters at their optimized positions, Int. J. Thermal Sciences 47(2007), 369-377.

4. A. Bejan, A. K. da Silva, G. Lorenzini. Distribution of heat sources in vertical open channels with natural convection. Int. J. Heat and Mass Transfer 50 (2005), 2139-2148.

5. V. A. F. Costa and A. M. Raimundo. Steady mixed convention in a differentially heated square enclosure with an active rotating circular cylinder, Int. J. Heat and Mass Transfer 53(5), 1208-1219 (2010).

6. S. H. Hussain, A. K. Hussein. Int. Communications in Heat and Mass Transfer 38(2), 263-274 (2011).

7. J. H.Bae, J. M. Hyun and J. W. Kim. Mixed convection in a channel with porous multiblocks under imposed thermal modulation, An Int. J. of computation and methodology, 46:9, 891-908.

8. C. Balaji, B. Premachandran. Conjugate mixed convection with surface radiation from a horizontal channel with protruding heat sources. International Journal of Heat and Mass Transfer 49(2006) 3568-3582.

9. A. Sharma, P.S. Mahapatra, N.K. Manna and Koushik Ghosh. Mixed convection in a baffled grovved channel, Indian academy of sciences 40(3), 835-849 (2015).

10. M.M. Rahman, H. F. Oztop, R. Saidur, Khaled-Al Salem. Finite element solution of MHD mixed convection in a channel with a fully or partially heated cavity, Elseveir, Computer \& Fluids 79(2013) 53-64.

11. N. Takahashi, E. Morita, Y. Inoue, Guannan XI, K. Inaoka and M. Senda. Heat transfer enhancement of a channel flow by rotation circular cylinder, JSME 81(2015), 823.

12. M. M. Billah, M. I. Khan, Mohammad M. Rahman, M. N. Hasan. Numerical study of mixed convection heat transfer enhancement in a channel with active flow modulation, AIP conference procedings 1851,020104 (2017). 